\title{
A teoria de justiça de Dworkin e sua aplicação no domínio dos transportes
}

\author{
Dworkin's theory of justice and its application in the domain of \\ transportation
}

\author{
Jessica Helena de Lima ${ }^{1}$, Maria Leonor Alves Maia² \\ ${ }^{1}$ Universidade Federal de Alagoas, Alagoas - Brasil, delima.jh@gmail.com \\ 2Universidade Federal de Pernambuco, Pernambuco - Brasil, nonamaia@gmail.com
}

\section{Recebido:}

6 de agosto de 2020

Aceito para publicação:

17 de agosto de 2021

Publicado:

23 de novembro de 2021

Editor de área:

Cira Souza Pitombo

\section{Palavras-chave:}

Teorias de justiça.

Equidade.

Justiça no transporte.

Dworkin.

\section{Keywords:}

Theories of justice.

Equity.

Transport justice.

Dworkin

DOI:10.14295/transportes.v28i4.2437

\begin{abstract}
RESUMO
As questões relativas à justiça e equidade nos transportes vêm crescendo em importância na literatura dos transportes nos últimos anos. No entanto, por tratar-se de um conceito normativo, a definição de equidade nos transportes perpassa pelo compreendimento de uma teoria de justiça e do significado de equidade no contexto desta teoria. Além disso, é preciso avaliar se é possível aplicar a lupa dos transportes a uma determinada teoria sem que a sua essencialidade lógica seja perdida. Este artigo revisa quatro teorias de justiça recorrentes na literatura e avalia criticamente as suas disposições considerando a perspectiva dos transportes e propõe B a utilização da teoria de Dworkin para o embasamento das análises. A escolha dessa teoria se deu por dois motivos principais: a) a linha de pensamento de Dworkin permite a extensão de sua teoria para analisar problemas específicos, sem a necessidade de desenvolver uma teoria mais abrangente de justiça social; e b) a noção de equidade de distribuição é diretamente ligada ao custo de prover a distribuição desejada.
\end{abstract}

\section{ABSTRACT}

Transport justice and equity issues have grown in importance in the transport literature in recent years. However, as it is a normative concept, the definition of equity in transport runs through the understanding of a theory of justice and the meaning of equity in the context of that theory. In addition, it is necessary to assess whether it is possible to apply the transport magnifying glass to a given theory without losing its logical essentiality. This article reviews four theories of justice recurrent in the literature and critically evaluates their provisions considering the perspective of transport, and proposes the use of Dworkin's theory to support the analyses. This theory was chosen for two main reasons: a) Dworkin's line of thought allows the extension of his theory to analyze specific problems, without the need to develop a more comprehensive theory of social justice; and b) the notion of equity in distribution is directly linked to the cost of providing the desired distribution.

\section{INTRODUCÃO}

0 debate sobre equidade nos transportes e transporte e justiça vem crescendo na literatura científica nos últimos anos. Recentemente, a literatura de transportes tem passado a se preocupar em não apenas medir as diferenças de acessibilidade ou exclusão social, mas em pautar suas análises sobre equidade nos transportes com base nas teorias de justiça contemporâneas. No entanto, os conceitos de equidade e justiça no contexto dos transportes permanecem com pouca clareza conceitual na literatura, o que dificulta a comparação de estudos e a formulação de políticas (Pereira et al., 2017; Martens, 2016). 
Justiça é um conceito normativo e, portanto, a sua definição não pode ser simplesmente lida no dicionário (Lima, 2020). Para determinar se as situações que vivenciamos são justas ou não, é preciso partir de uma teoria que defina os critérios necessários para equidade e justiça (Dworkin, 2012). As mais famosas teorias de justiça do século XX e XXI são ditas liberais por considerarem que as liberdades individuais das pessoas precisam ser garantidas conquanto estas não prejudiquem a liberdade das demais. Elas também estão vinculadas à noção de igualdade na distribuição de bens na sociedade, definindo quem são os concernidos pela teoria (por exemplo, se a teoria engloba apenas seres humanos ou também outros seres vivos) e o que deve ser igualado para que haja justiça (as teorias divergem sobre o que deve ser igualado, bens primários, recursos, capabilities, etc.) (Ribeiro, 2015).

No entanto, as teorias de Justiça Social costumam desconsiderar o espaço, permitindo assim que o transporte seja negligenciado, já que o transporte existe porque existem deslocamentos/espaços para serem vencidos (Harvey, 1990). Desta forma, as análises de justiça social no domínio dos transportes não podem meramente aplicar as teorias de justiça social ao setor. As extrapolações precisam estender a teoria para que passe a considerar a espacialidade da vida em sociedade, posto que as teorias de justiça social são fundamentalmente a-espaciais (Pirie, 1983). Assim, este artigo dedica-se a apresentar as teorias de justiça social, buscando responder à seguinte pergunta: dentre as teorias de justiça qual seria a mais adequada para embasar discussões no domínio dos transportes e as complicações derivadas deste pleito?

0 artigo avalia o conceito de equidade e justiça, fazendo ponderações sobre o seu uso no transporte, considerando as teorias do utilitarismo, igualitarismo de Rawls, abordagem das $\mathrm{Ca}$ pabilities de Sen e Nussbaum e Igualdade de Recursos de Dworkin. Neste sentido, considerando as condições de desigualdade presentes no Brasil, precisa-se avaliar equidade a partir da prerrogativa de que todos devem ter disponibilidade e acesso ao sistema de transporte público. Após avaliar as teorias, argumenta-se em prol da utilização da teoria de justiça proposta por Ronald Dworkin, para quem uma sociedade é justa se todos tiverem recursos iguais. A escolha dessa teoria se deu por dois motivos principais: a) a linha de pensamento de Dworkin permite a extensão de sua teoria para analisar problemas específicos, sem a necessidade de desenvolver uma teoria mais abrangente de justiça social; e b) a noção de equidade de distribuição é diretamente ligada ao custo de prover a distribuição desejada.

\section{TEORIAS DE JUSTIÇA}

A justiça social está vinculada à noção de igualdade na distribuição de bens na sociedade. Desta forma, as teorias de justiça visam responder a duas questões fundamentais: i) quem são os concernidos (por exemplo, se a teoria engloba apenas seres humanos ou também outros seres vivos) e; ii) o que igualar para os propósitos de justiça (as teorias divergem sobre o que deve ser igualado, bens primários, recursos, capabilities, etc.) (Ribeiro, 2015).

Para que uma teoria de justiça seja formulada, de acordo com Rawls (2003), são necessárias duas circunstâncias: a condição subjetiva do pluralismo moral e a condição objetiva da limitação de recursos. Ou seja, se tivéssemos os recursos suficientes para satisfazer as nossas necessidades e se estivéssemos de acordo sobre quais necessidades precisam ser satisfeitas não existiria um problema de justiça.

As teorias aqui detalhadas foram escolhidas com base na revisão da literatura a partir da constância de citações em livros ou artigos sobre teorias de justiça ou que relacionam as teorias de justiça a problemas de transporte (Roemer, 1998; Furquim, 2010; Martens, 2016; Pereira et 
al., 2017, Dias, 2018). As teorias liberais de justiça mais frequentemente citadas foram: o Utilitarismo, cujos autores principais são Stuart Mill, Jeremy Bentham e Peter Singer, o Igualitarismo de John Rawls, a Abordagem das Capabilities de Amartya Sen e Martha Nussbaum e a Teoria da Igualdade de Recursos de Dworkin. Tais teorias são classificadas como liberais por partirem de uma perspectiva que tem como foco a garantia das liberdades individuais. Ou seja, um indivíduo pode levar a sua vida como queira desde que não prejudique a liberdade de outro indivíduo. Além dessa valorização da liberdade todas elas partem dos seguintes pressupostos:

i. O capitalismo como forma de sociedade, desconsiderando a possibilidade de outras formas de organização da sociedade. Limitam-se a pensar o como promover a justiça dentro do sistema atual, capitalista, adotando o mercado como mecanismo de troca.

ii. Não existem conflitos entre as classes de maneira explícita.

iii. Separam a esfera da produção e a esfera da distribuição.

iv. Supõem a neutralidade do Estado, como se o Estado estivesse dissociado dos produtores e não os servisse.

As próximas seções se dedicam a introduzir a teoria de justiça e refletir sobre a sua viabilidade de uso no âmbito dos transportes. A seção três aborda as teorias utilitaristas, a seção quatro discorre sobre o Igualitarismo de Rawls, a seção cinco faz considerações sobre a abordagem de Capabilities de Sen e Nussbaum e a seção seis apresenta a Igualdade de Recursos de Dworkin seguida de uma seção de discussão e conclusão.

\section{UTILITARISMO}

O utilitarismo, originado da obra de filósofos e economistas ingleses nos séculos XVIII e XIX, busca como foco do valor moral a capacidade de promover o prazer e minimizar o sofrimento. Seus principais expoentes foram os pensadores Jeremy Bentham - cujo foco era quantitativo, a maior quantidade de prazer; John Stuart Mill - focado em uma satisfação qualitativa; e Peter Singer - que acreditava que não só os seres humanos deveriam ser considerados. Trata-se de uma das mais influentes teorias de justiça usadas no domínio dos transportes por fornecer alicerce teórico às populares análises de custo-benefício (Hausman e Mcpherson, 2006; Martens, 2016).

De acordo com Pereira et al. (2017), o utilitarismo é baseado em três assunções básicas que estruturam o seu entendimento do que seria justiça:

i. O bem-estar humano (utilidade) é a única coisa com valor intrínseco e, por isso, o centro das preocupações da justiça (Kymlicka, 2002).

ii. Interpretam o princípio de igual respeito dando peso igual aos interesses e ao bem-estar de todos, atendendo ao princípio aristotélico da igualdade numérica, não importando as preferências ou a situação material individual.

iii. Têm uma visão consequencialista. 0 julgamento moral de uma ação ou política deveria ser baseado exclusivamente nas suas consequências, particularmente como ele maximiza o bem-estar.

As políticas passam a ser uma questão de gestão eficiente onde basta encontrar a alternativa capaz de maximizar o bem-estar agregado para o maior número de pessoas (Kymlicka, 2002). Martens (2011) e Van Wee (2012), questionam que a utilidade de uma atividade é comumente medida pela propensão de pagar das pessoas e, como os benefícios de projetos de transportes 
são tradicionalmente medidos em termos de economias do valor monetário do tempo de viagem, uma das consequências é que são priorizados os ganhos de acessibilidade das atividades que geram mais lucro, ou seja, a acessibilidade das pessoas de maior renda. Esta crítica pode se estender às análises tradicionais de Custo-Benefício, dado que estas se servem da lógica utilitarista.

Portanto, o modelo tende a intensificar desigualdades, uma vez que não se preocupa em determinar como o bem-estar será distribuído entre as pessoas. Este fato pode ser um problema, pois o aumento do bem-estar geral pode ser devido ao ônus dos mais pobres (Sen, 2009). Um exemplo típico da área de transportes são as desapropriações de áreas marginais a rodovias para ampliação de vias, pois, em geral, uma grande quantidade de famílias é deslocada à revelia, muitas vezes para locais mais distantes e menos acessíveis, para permitir uma maior fluidez para os veículos particulares.

O utilitarismo se vale do princípio da compensação de Kaldor-Hicks, para justificar suas inclinações classistas. De acordo com este princípio, um projeto é equitativo e viável se os benefícios são grandes o suficiente de forma que os vencedores superam os perdedores mesmo não sendo previsto nenhum tipo de compensação aos perdedores (Hausman e Mcpherson, 2006). Quer dizer, se uma determinada intervenção melhorar a mobilidade e a acessibilidade para as classes mais altas e usuárias do carro e, tiver o efeito inverso para as classes mais pobres e usuárias do transporte público, por exemplo, o princípio de compensação garante que não existe problema moral.

O princípio contrário, beneficiar as classes mais baixas em detrimento das classes mais altas, dificilmente é justificável na lógica dessa teoria pois, como a utilidade é medida pela propensão de pagar das pessoas, são priorizados os ganhos de acessibilidade das atividades mais lucrativas, ou seja, a acessibilidade das pessoas de maior renda.

Outra crítica que pode ser tecida ao utilitarismo é que o modelo negligencia que as preferências de alguns indivíduos podem vir ilegitimamente a violar os direitos e reduzir a liberdade dos outros, como é o caso, por exemplo, de permitir que veículos circulem acima da velocidade permitida em cidades. Esta atitude coloca em risco a vida dos demais habitantes e limita a liberdade, por exemplo, de ciclistas usarem a via, se esta for uma prática comum (Kymlicka, 2002).

\section{IGUALITARISMO DE RAWLS}

O Igualitarismo vem no sentido de contrapor o pensamento utilitarista que dominava o mundo até a década de 1970, quando Rawls publicou o seu livro Teoria de Justiça. Para Rawls, se precisássemos criar um sistema social e político existente sob um "véu de ignorância" - ou seja, se nada soubéssemos sobre o lugar que ocuparíamos neste sistema -, não haveria outra alternativa senão escolher a sociedade que valoriza os menos favorecidos. Portanto, uma sociedade justa seria a que a pessoa menos favorecida é a que tem mais vantagens de manter a sua dignidade individual (Rawls, 1971).

Na visão de Rawls, para que uma sociedade seja considerada justa é preciso atender a dois princípios fundamentais: a liberdade e a igualdade. Pelo princípio da liberdade, todas as pessoas têm as mesmas demandas para liberdades básicas. 0 princípio da igualdade coloca que as desigualdades sociais e econômicas devem ser ordenadas de maneira que ao mesmo tempo sejam consideradas vantajosas para todos dentro dos limites do razoável (princípio da diferença), 
e que as posições e cargos também sejam acessíveis a todos (princípio da igualdade de oportunidades). Ou seja, não basta que as vagas de empregos sejam abertas, mas que todos os indivíduos tenham chance de obtê-las (Rawls, 1971).

Além dos princípios de justiça, Rawls $(1971,1982,2003)$ distingue cinco bens sociais primários, que seriam inerentes a uma sociedade justa:

i. Um conjunto de direitos básico e liberdades, incluindo liberdade de pensamento e associação, liberdade definida pela integridade da pessoa, e assim por diante.

ii. Liberdade de movimento e livre escolha de ocupação no contexto de oportunidades diversas.

iii. As capacidades e prerrogativas de posições e cargos de responsabilidade: propiciam à pessoa amplo espaço para diferentes capacidades sociais e de autogoverno.

iv. Renda e riqueza, entendidos em amplo sentido como meios polivalentes: renda e riqueza são necessárias, direta ou indiretamente, para a realização de ampla gama de fins, quaisquer que sejam.

v. As bases sociais do autorrespeito: trata-se daqueles aspectos das instituições básicas que são essenciais para que os cidadãos adquiram um sentimento vigoroso de seu valor como pessoas e para que sejam capazes de desenvolver e exercer suas faculdades morais e promover seus objetivos e fins com autoconfiança.

Considerando a perspectiva dos transportes, apesar de autores com Khisty (1996), Langmyhr (1997), Viegas (2001) e Tyler (2006) terem aplicado o conceito de justiça como equidade de Rawls aos transportes, Martens (2016) afirma que ele não poderia ser diretamente aplicado posto que o princípio foi desenvolvido para uma única instância de aplicação que é a estrutura básica da sociedade. Ou seja, a teoria foi desenvolvida para explicar a sociedade, ela não pode ser diretamente replicada para abordar aspectos específicos como o transporte ou a acessibilidade.

Uma possibilidade seria considerar a acessibilidade como um bem primário adicional, argumentando que acessibilidade é um pré-requisito para obter renda e dinheiro e também cargos e posições. A questão é que essa adição gera um problema de comparação interpessoal. Entretanto, o próprio Rawls coloca que a aplicação do princípio da diferença como um princípio individual é absurda (Rawls, 2003, pg. 72).

No contexto da sociedade brasileira, Dias (2018) critica a aplicação do Igualitarismo de Rawls com base em dois fatores: i) Rawls afirma que sua teoria serve apenas para sociedades ditas bem-ordenadas, com condições mínimas socioeconômicas, e não afligidas por carência extrema de recursos e/ou instituições frágeis e desestruturadas, por razões socioculturais (o que difere essencialmente da realidade brasileira atual); e ii) apenas indivíduos socialmente ativos, livres, racionais e razoáveis, que representam instituições podem arbitrar sobre o que seria justo (não é toda a sociedade que pode opinar sobre o que seria justo).

Com base nestes argumentos, considera-se que não é possível limitar a teoria de Rawls ao contexto específico do transporte, uma vez que o próprio autor considera tal aplicação inviável e, mesmo que ela fosse possível, não seria uma abordagem adequada ao cenário brasileiro, como esclarece Dias (2018). 


\section{ABORDAGEM DA CAPABILITIES DE SEN E NUSSBAUM}

Amartya Sen inspirou o seu trabalho sobre justiça social pautado em liberdades e capabilities individuais na teoria de Justiça de Rawls. Entretanto, para Sen, o foco principal não deveria ser os bens primários e, sim, as capabilities. Uma sociedade seria justa se nela os indivíduos pudessem escolher, dentre os pacotes de capacity e alternativas disponíveis, aquele que promovesse a sua realização enquanto agente (Sen, 1979, 2006, 2009).

Capabilities, para Amartya Sen é mais abrangente do que capacidade (capacity), envolvendo não somente a capacidade, mas também a habilidade necessária para realizar um determinado funcionamento (functioning). As capabilities podem ser definidas como os conjuntos de liberdades e oportunidades que estão disponíveis para que os indivíduos escolham a depender de uma combinação de habilidades pessoais e do ambiente político, econômico e social. Além das capabilities, são definidos os conceitos de capacity, as várias combinações de estados e ações inter-relacionadas que uma pessoa pode realizar e os funcionamentos que se referem a cada ação ou estado que compõe as diversas opções de combinações disponíveis (Nussbaum, 2011).

Assim, na Abordagem das Capabilities, o mais importante não é o que as pessoas possuem, mas a habilidade pessoal dos indivíduos de converter os recursos que possuem em uma vida confortável. De acordo com Sen (2009), os bens materiais são apenas meios para alcançar o bem-estar. A principal preocupação da AC é na promoção de uma igualdade básica de capabilities de forma a garantir um nível mínimo aceitável de capabilities. Este nível pode variar de sociedade para sociedade tendo em vista diferentes fatores culturais.

Ao analisar o trabalho de Sen, Nussbaum (2007) argumenta que, apesar dos fatores culturais, é preciso que sejam garantidas 10 capabilities básicas: 1) vida, 2) saúde corporal, 3) integridade física, 4) sensações, imaginação e pensamento, 5) emoções, 6) racionalidade prática, 7) afiliação, 8) relação com seres de outras espécies, 9) lúdico, 10) controle sobre ambiente (político e ambiental).

Diversos autores, ao buscar trazer a teoria de Sen para a perspectiva dos transportes consideram a mobilidade como uma capability, uma vez que ela permite a satisfação de necessidades básicas (Sen, 2006; Beyazit, 2011; Van Wee, 2012). A ideia de mobilidade como capability deveria ser expandida para a ideia de acessibilidade como capability uma vez que este conceito trata da capacidade do indivíduo de alcançar bens, serviços, atividades e destinos que juntos são chamados de oportunidades e não apenas da capacidade de se movimentar.

É preciso, entretanto, ressaltar duas críticas à análise da acessibilidade enquanto capability:

i. Por exemplo, Farrington e Farrington (2005) e Hananel e Berechnam (2016) consideram que tomar a acessibilidade como uma capability torna a necessidade por acesso uma condição fundamental e necessária para alcançar direitos básicos como ir à escola, receber cuidados de saúde e poder ir votar. Isto significa determinar um nível mínimo de acessibilidade, algo variável de sociedade para sociedade em razão das diferentes culturas, e que jaz irresolvido na literatura acadêmica dos transportes.

ii. Para Pereira et al. (2017) o termo acessibilidade hoje é usado na literatura de transportes, em geral, como uma perspectiva geográfica baseada na quantidade de equipamentos de serviço que uma região possui (acessibilidade locacional) ou uma pessoa é capaz de alcançar em um raio (acessibilidade pessoal). Entender a acessibilidade enquanto capability significa inserir um novo fator às análises: a habilidade pessoal de acessar e usar tecnologias de mobilidade e serviços de transporte. Esta habilidade pode estar 
relacionada a fatores pessoais (como aptidões físicas e mentais, perícia motora e cognitiva para entender e interagir com o sistema de transportes, experiência acumulada e recursos financeiros) ou fatores externos (como abuso sexual e discriminação, projeto físico do sistema, provisões para pessoas com deficiência, preço da tarifa, informação).

A Abordagem das Capabilities se preocupa com a liberdade de movimento e escolha humana, já que depende tanto de atributos dos indivíduos quanto da sua interação com o ambiente. Mesmo considerando a definição de acessibilidade baseada no indivíduo, ainda assim existem diversas formas de medir as possíveis interações e variações (baseadas na utilidade, medidas de espaço-tempo, etc.). No momento, não há consenso sobre uma medida de acessibilidade que supere os dados clássicos coletados em pesquisas de transportes (Pereira et al., 2017). Desta forma, considera-se que a aplicação da Abordagem das Capabilities é limitada para orientar a equidade em políticas de transporte.

\section{IGUALDADE DE RECURSOS DE DWORKIN}

Ronald Dworkin reconhece que existem desigualdades na sociedade, não só de recursos impessoais, bens ou ativos que poderiam ser comercializados ou transferidos em leilões, mas também, desigualdades relativas a recursos pessoais, características físicas, mentais, emocionais e dons que por sua vez não podem ser transferidos ou comercializados. Numa sociedade é justa todos recursos presentes nela precisam ser igualmente distribuídos para todos. Neste sentido, para resolver a questão dos recursos pessoais é criado um sistema de seguros, que será melhor explanado ao decorrer desta seção (Dworkin, 2005).

0 modelo é ilustrado por uma ilha deserta onde pessoas recém-chegadas (imigrantes) precisam estabelecer regras de convivência e distribuição de bens de forma que todos possuam os mesmos direitos. Inicialmente, todos os imigrantes recebem uma igual quantidade de conchas (moeda de troca) e institui-se um leilão onde cada imigrante poderá trocar suas conchas pelos bens (por exemplo: localização residencial ou serviços de transporte) que deseja ter na nova sociedade insular. Os componentes dessa lista de bens, em teoria atendem a todos os desejos dos que estão na ilha.

O leilão sucede da seguinte forma: i) cada lote do leilão apresentará um preço determinado pelo leiloeiro; ii) o conjunto de preços atende a todos os mercados, significando que haverá apenas um comprador para cada preço e todos os lotes deverão ser vendidos; iii) para que o leilão seja efetivo, são necessários dois princípios fundamentais: autenticidade e independência. 0 princípio de autenticidade irá garantir que as preferências dos integrantes na ilha deserta serão dos próprios indivíduos e não impostas por alguma entidade ou outro indivíduo. 0 princípio da independência assegura que as escolhas dos imigrantes não são influenciadas por preconceito (Dworkin, 2002; Pierik e Robeyns, 2007).

O leilão deverá durar até que todos os integrantes da ilha estejam satisfeitos com a sua cesta de bens e não exista cobiça pela cesta alheiai. Nenhuma divisão de recursos é uma divisão igualitária se, uma vez concluída a divisão, qualquer imigrante preferir a cesta de recursos de outra pessoa à sua própria cesta (Dworkin, 2005). Assim, a proposição de um sistema de leilão não apenas resolve a questão de uma igual divisão de recursos, na qual cada pessoa tem uma cesta de recursos idêntica, em termos de justiça, mas também em termos de eficiência, pois o leilão permite que todas as pessoas comprem um pacote de mercadorias que melhor corresponda às suas preferências (Martens, 2016). 
Para Furquim (2010), a ideia do leilão igualitário da teoria da igualdade de recursos, apenas funcionará se a hipótese inicial for confirmada, ou seja, os imigrantes entrarem no leilão em igualdade de condições. Considerando o setor de transportes, no mundo real, no entanto, tal hipótese não pode ser confirmada, uma vez que este setor é caracterizado por diversas falhas de mercado, tais quais assimetria de informações e concorrência imperfeita. Apesar disto, a proposta da teoria de Dworkin é que o seu mecanismo seja capaz de proporcionar um padrão para avaliar o quão desigual ou injusta é a distribuição de recursos de uma comunidade.

0 teste de inveja mostra que a injustiça está relacionada a ter menos recursos considerando as circunstâncias em que se vive, como por exemplo, pessoas com terras menos férteis. E, também, que pode acomodar as diferentes escolhas de vida dos indivíduos, enquanto alguns almejam uma vida de sucesso no mercado financeiro, outros podem preferir aderir à permacultura (Clayton, 2002).

Para Clayton (2002), diferentemente da igualdade utilitarista e da igualdade pelos bens-primários de Rawls, que colocam que existe uma lista de bens que as pessoas deveriam possuir, a igualdade de recursos não busca determinar tal lista. As pessoas escolherão os recursos impessoais ou bens no mercado, de acordo com uma parcela justa de 'dinheiro' que lhes cabe, e de acordo com o que elas consideram ser útil para o seu bem-estar. Para Dworkin, portanto, não existe uma concepção concreta do que seria a boa vida. Como na teoria de Dworkin não existe uma lista pré-definida do que seriam os bens primários, semelhantemente ao que ocorre nas teorias de Rawls e na Abordagem das Capabilities o transporte pode hipoteticamente participar da composição da cesta de bens.

Sob a teoria da igualdade de recursos, as pessoas podem decidir que tipo de vida buscam considerando um contexto de informações sobre o custo real que suas escolhas impõem a outras pessoas e, portanto, sobre o estoque total de recursos que podem ser razoavelmente usados por elas (Dworkin, 2001). As escolhas que os indivíduos fazem são influenciadas por três aspectos: hábito, sorte e oportunidade. Os indivíduos definem suas preferências e, a partir daí, é possível perguntar se eles tiveram êxito em relação ao que planejaram para suas vidas. É provável que o valor atribuído ao êxito e ao fracasso pessoal varie entre os indivíduos. Dworkin denomina este fenômeno de êxito relativo (Furquim, 2010).

Após o leilão inicial, Dworkin (2001) busca abordar problemas mais abrangentes como o trabalho, comércio e investimentos. Ele então institui duas formas de sorte: por opção e a bruta. A sorte por opção resulta das escolhas voluntárias dos indivíduos. A sorte bruta se refere aos casos nos quais a pessoa não tem influência alguma em um evento particular. No que se refere à sorte por opção, para Dworkin (2001), não há motivos para negar que um indivíduo que resolveu se arriscar mais, e que tenha conseguido com isso mais recursos, disfrute desses recursos. Nos casos de sorte bruta por falta de escolha, é preciso buscar uma forma de compensar a má sorte dos indivíduos. Para estas situações Dworkin sugere um seguro hipotético que cada imigrante deveria adquirir contra a sorte bruta (invalidez, doenças crônicas, etc.).

Outra questão relevante para Dworkin (2001) é o talento. Se o teste de inveja é necessário para uma distribuição igualitária, o talento precisa ser amenizado. Para tal, o autor propõe uma taxação progressiva da renda, de forma a periodicamente redistribuir os recursos. Ele assume que o problema dos talentos deve ser tratado de maneira similar às deficiências: cada indivíduo seria indagado sobre o quanto estaria disposto a pagar caso não possuísse um talento específico e este valor seria convertido em taxações sobre a renda (Dworkin, 2001). 
Dworkin não proporciona uma solução total e incontestável para disparidades de renda advindas de diferenças de talento. Ele aponta que um ideal de igualdade deve considerar um programa redistributivo para diferenças de talento, uma vez que estas não são frutos da escolha, são objeto da sorte ou azar bruto. A taxação progressiva existe no mundo real, chegando a tributos sobre fortunas de $90 \%$, em países desenvolvidos, permitindo que a população disponha de serviços públicos de saúde, educação, segurança e seguridade social de qualidade, sem interferir no seu crescimento econômico (Furquim, 2010). Neste sentido, considerando a perspectiva dos transportes, a teoria de Dworkin nos permite justificar a criação de um fundo de transportes de forma a garantir que todos os indivíduos tenham acesso a um nível mínimo de transporte. Todos devem ter acesso ao transporte público, alguns podem ter acesso também ao uso de veículos individuais, mas isso não os exclui da contribuição com um fundo de transportes que garanta o acesso ao transporte público.

Tabela 1 - Resumo dos cenários hipotéticos desenhados para trazer os princípios de justiça ao domínio dos transportes

\begin{tabular}{|c|c|c|c|}
\hline Caso & enário & Descrição & Seguro \\
\hline 1 & O caso básico. & $\begin{array}{l}\text { Os imigrantes fazem uma oferta por uma locação residen- } \\
\text { cial, num contexto de um sistema de transporte único que } \\
\text { pode ser usado por todos. }\end{array}$ & $\begin{array}{l}\text { Nenhum, é uma situação onde existem diferenças, } \\
\text { mas elas são justas, os níveis de acessibilidade irão } \\
\text { emergir. }\end{array}$ \\
\hline 2 & $\begin{array}{l}\text { Ofertas no } \\
\text { transporte. }\end{array}$ & $\begin{array}{l}\text { Imigrantes fazem ofertas para vários pacotes de serviço, } \\
\text { uma vez que o sistema da ilha não é previamente estabele- } \\
\text { cido. }\end{array}$ & $\begin{array}{l}\text { Nenhum, é provável que o leilão resulte em um nú- } \\
\text { mero limitado de serviços de transportes coexistindo, } \\
\text { provendo níveis diferentes, mas justos de acessibili- } \\
\text { dade. }\end{array}$ \\
\hline 3 & $\begin{array}{l}\text { Licitando } \\
\text { serviços de } \\
\text { transporte à } \\
\text { prova de } \\
\text { deficiências. }\end{array}$ & $\begin{array}{l}\text { Imigrantes licitam vários pacotes de serviços no entendi- } \\
\text { mento de que eles podem ser excluídos do uso de determi- } \\
\text { nados pacotes no caso de deficiências relacionadas ao des- } \\
\text { locamento. }\end{array}$ & $\begin{array}{l}\text { Dependendo das circunstâncias os imigrantes podem } \\
\text { adquirir um sistema de transporte mais barato, po- } \\
\text { rém que parcialmente exclui algumas pessoas ao in- } \\
\text { vés de um completamente inclusivo. Neste caso os } \\
\text { imigrantes irão adquirir também um sistema de } \\
\text { transporte adicional que garante um nível menor, } \\
\text { mas suficiente de acessibilidade para todos os mem- } \\
\text { bros da sociedade excluídos do sistema principal. }\end{array}$ \\
\hline 4 & $\begin{array}{l}\text { Seguro contra } \\
\text { diferenças de } \\
\text { renda justas }\end{array}$ & $\begin{array}{l}\text { Em contraste com os cenários anteriores, os imigrantes sa- } \\
\text { bem do risco de receber apenas o salário base. Uma vez a } \\
\text { vida na ilha comece, eles podem licitar um seguro adicional } \\
\text { contra este risco. }\end{array}$ & $\begin{array}{l}\text { Os imigrantes aceitam as consequências de um nível } \\
\text { básico de renda em termos de menos possibilidades } \\
\text { de escolha da locação residencial; eles não compram } \\
\text { um seguro extra. }\end{array}$ \\
\hline 5 & $\begin{array}{l}\text { Seguro contra } \\
\text { diferenças de } \\
\text { renda injustas }\end{array}$ & $\begin{array}{l}\text { Em contraste com o cenário anterior, os imigrantes têm o } \\
\text { risco de receber uma renda muito abaixo do nível base uma } \\
\text { vez que a vida na ilha comece, eles podem licitar um seguro } \\
\text { adicional contra esse risco. }\end{array}$ & $\begin{array}{l}\text { Os imigrantes compram um seguro que é utilizado } \\
\text { para um serviço de transporte de baixo custo ou para } \\
\text { subsídios de transporte para reduzir o déficit. }\end{array}$ \\
\hline 6 & $\begin{array}{l}\text { Seguro contra } \\
\text { localização } \\
\text { aleatória }\end{array}$ & $\begin{array}{l}\text { O caso da acessibilidade insuficiente. Os imigrantes não po- } \\
\text { dem escolher a sua locação residencial e têm o risco de se- } \\
\text { rem alocados na periferia com um nível de acessibilidade } \\
\text { insuficiente. Eles podem licitar um seguro para se proteger } \\
\text { contra esse risco. }\end{array}$ & $\begin{array}{l}\text { Os imigrantes provavelmente aceitariam esta forma } \\
\text { de má sorte bruta, uma vez que se espera que os se- } \\
\text { guros que garantem acessibilidade suficiente sejam } \\
\text { inibitivamente caros. Apenas se a probabilidade } \\
\text { desta forma de má sorte bruta for alta, os imigrantes } \\
\text { podem comprar um seguro que garanta alguma me- } \\
\text { Ihora, mas não um nível suficiente de acessibilidade. }\end{array}$ \\
\hline 7 & $\begin{array}{l}\text { Seguro contra } \\
\text { localização } \\
\text { aleatória }\end{array}$ & $\begin{array}{l}\text { O caso da deficiência relacionada ao transporte. Os imi- } \\
\text { grantes não podem escolher a sua locação residencial, cor- } \\
\text { rem o risco de serem alocados em uma região periférica } \\
\text { com acessibilidade suficiente pelo meio de transporte do- } \\
\text { minante, mas sem acessibilidade suficiente para o meio de } \\
\text { transporte alternativo para pessoas com deficiências relaci- } \\
\text { onadas ao transporte. Os imigrantes podem pedir por um } \\
\text { seguro para proteger-se contra esse risco. }\end{array}$ & $\begin{array}{l}\text { Dependendo das circunstâncias, principalmente da ri- } \\
\text { queza da sociedade e do tamanho do risco, os imi- } \\
\text { grantes podem tanto comprar um seguro para me- } \\
\text { Ihorar um sistema de transporte alternativo ou não } \\
\text { comprar o seguro e aceitar as consequências da aces- } \\
\text { sibilidade insuficiente, ou mudar de casa. }\end{array}$ \\
\hline 8 & $\begin{array}{l}\text { Seguro contra } \\
\text { localização } \\
\text { aleatória }\end{array}$ & $\begin{array}{l}\text { O caso dos aluguéis caros demais. Os imigrantes não podem } \\
\text { escolher o seu local de residência e correm o risco de serem } \\
\text { alocados em uma locação com nível suficiente de acessibi- } \\
\text { lidade, mas com aluguéis caros demais. Os imigrantes po- } \\
\text { dem licitar um seguro para se proteger contra esse risco. }\end{array}$ & $\begin{array}{l}\text { Os imigrantes irão provavelmente comprar um se- } \\
\text { guro de locação de preço acessível para proteger os } \\
\text { seus interesses de continuar vivendo em sua residên- } \\
\text { cia original. }\end{array}$ \\
\hline
\end{tabular}


A teoria da igualdade de recursos de Dworkin não objetiva eliminar as apostas ou a sorte das pessoas, mas torná-las iguais em recursos para enfrentar as incertezas (Furquim, 2010). "Igualdade de recursos significa que as pessoas devem estar igualmente situadas em relação ao risco, em vez de estarem igualmente situadas depois de serem resolvidas as incertezas do risco" (Dworkin, 2002). Para tal, o autor usa dispositivos econô micos familiares de forma a estabelecer uma métrica de sensibilidade das condições morais para propriedade (leilão), transferência (mercado ideal) e remuneração (seguro hipotético) (Guest, 2009).

Para o autor, a situação típica dos países desenvolvidos, e de um número cada vez maior de países em desenvolvimento, no que toca os transportes, é caracterizada por um sistema dominante de carros e vias que moldam os padrões de uso do solo. Neste sistema, uma parcela substancial da população é impossibilitada de usá-lo pois, vive com uma renda de subsistência abaixo de um piso justo e/ou habita em residências muito distantes e muito pouco acessíveis. Essas condições moldam fortemente os padrões de acessibilidade vivenciados por pessoas da vida real.

Considerando a acessibilidade nos transportes à luz da teoria de Dworkin, Martens (2016) propõe os cenários hipotéticos e respectivas soluções de seguros conforme apresentado na Tabela 1.

Martens (2016) então agrupa os cenários e identifica de três formas básicas de seguro de acessibilidade que devem proteger as pessoas contra as formas subjacentes de má sorte bruta relacionada à acessibilidade que acontecem no mundo real. 0 resumo é apresentado na Tabela 2.

Tabela 2 - Tipos de seguro para se proteger da má sorte bruta na acessibilidade e seu detalhamento

\begin{tabular}{|c|c|}
\hline Seguro & Detalhamento \\
\hline $\begin{array}{l}\text { 1. Proteger as pessoas de serem incapazes de } \\
\text { usar o sistema de transporte dominante de- } \\
\text { vido a deficiências relacionadas a viagens. }\end{array}$ & $\begin{array}{l}\text { A forma dos serviços de transporte oferecidos a pessoas com deficiências relacionadas a via- } \\
\text { gens é de natureza aberta: pode consistir em serviços de táxi individuais subsidiados, serviços } \\
\text { de transporte público com base em horários acessíveis, serviços transporte alternativo sob } \\
\text { demanda e assim por diante. Qualquer que seja o tipo de serviço oferecido, suas qualidades } \\
\text { devem ser tais que as pessoas realmente possam usá-lo para participar de suas atividades. }\end{array}$ \\
\hline $\begin{array}{l}\text { 2. proteger as pessoas contra o risco de não } \\
\text { poder usar o sistema de transporte dominante } \\
\text { por razões de custo. }\end{array}$ & $\begin{array}{l}\text { O seguro garante acessibilidade suficiente por meio de subsídios em dinheiro que reduzem os } \\
\text { custos do uso do sistema de transporte dominante ou pela prestação de um serviço de trans- } \\
\text { porte alternativo e de baixo preço. Geralmente se dá por um sistema de transporte subsidiado } \\
\text { ou por subsídios ao uso de um veículo motorizado. Alguns governos subsidiam a compra ou o } \\
\text { uso de automóveis para famílias de baixa renda, enquanto praticamente todos os países de- } \\
\text { senvolvidos subsidiam serviços de transporte público para permitir viagens para pessoas de } \\
\text { baixa renda. É preciso considerar ainda que o tamanho do subsídio pode variar de acordo com } \\
\text { a localização, já que localizações mais baratas tendem a ter menor acessibilidade e que qual- } \\
\text { quer pessoa que receba acima do nível de renda considerado justo deve pagar o custo total } \\
\text { do transporte. }\end{array}$ \\
\hline $\begin{array}{l}\text { 3. Proteger pessoas contra o risco da acessibi- } \\
\text { lidade insuficiente devido à localização. }\end{array}$ & $\begin{array}{l}\text { Diversas situações são possíveis. A) as pessoas podem ter um nível insuficiente de acessibili- } \\
\text { dade, mas com um sistema de transporte que funciona bem. Neste caso a melhora da acessi- } \\
\text { bilidade se dá através de políticas de uso do solo. Resulta apenas em uma cobertura parcial. } \\
\text { B) as pessoas podem residir em localizações de custo proibitivo por causa do alto custo dos } \\
\text { aluguéis ou do transporte. Essas pessoas devem ter um subsídio que as ajude a manter a resi- } \\
\text { dência e um nível adequado de acessibilidade. C) As pessoas podem ter um nível de acessibi- } \\
\text { lidade adequado com um bom sistema de transporte, mas não poderem usá-lo por motivos } \\
\text { de deficiência. Apenas uma cobertura parcial é garantida uma vez que pode ser caro demais } \\
\text { manter um sistema alternativo que garanta um nível de acessibilidade adequado a todos os } \\
\text { lugares. }\end{array}$ \\
\hline
\end{tabular}

Considerando as definições expostas na Tabela 2, do que pode ser considerado digno da criação de um seguro, de acordo com a análise da teoria de Dworkin com foco na acessibilidade desenvolvida por Martens (2016), é possível determinar quais aspectos devem considerados para operacionalizar a noção de equidade, de forma a afirmar que uma determinada medida ou 
sistema de transporte, é capaz de promover uma maior equidade no que diz respeito a acessibilidade dos indivíduos. Desta forma, um modo de transporte, estará atuando para a promoção da equidade se, por seus atributos for capaz de:

i. proteger as pessoas de serem incapazes de usar o sistema de transporte dominante devido a deficiências relacionadas a viagens;

ii. proteger as pessoas contra o risco de não poder usar o sistema de transporte dominante por razões de custo;

iii. proteger pessoas contra o risco da acessibilidade insuficiente devido à localização.

Analogamente, caso atue no sentido reverso, um modo de transporte, estaria contribuindo para uma diminuição da equidade se o seu uso:

i. aumentar a quantidade de pessoas incapazes de usar o sistema de transporte dominante em razão de deficiências relacionadas a viagens;

ii. aumentar o risco de não se capaz de utilizar o sistema de transporte dominante por razões de custo;

iii. aumentar o risco de da acessibilidade insuficiente devido à localização.

Desta forma, a teoria da Igualdade de Recursos de Dworkin reconhece a diversidade entre os indivíduos, que o território não ubíquo com relação à acessibilidade e que existem diferentes níveis de acesso ao sistema de transporte e que este pode atuar na promoção ou diminuição da equidade, como exposto acima.

A partir do reconhecimento das diferenças, a teoria cria sistemas de compensação capazes de equalizar as diferenças, ao mesmo tempo em que garante o acesso a uma cesta básica de consumo que, no caso do transporte, considera-se que seria um nível básico de acessibilidade ao transporte público. No caso da ausência da garantia de acesso a esse sistema básico de transporte, é criada uma compensação (seguro) que permitiria diminuir o impacto negativo dessa falta de acessibilidade.

Em sociedades onde há grandes disparidades socioeconômicas, como o Brasil, a teoria de Dworkin institui-se como um arcabouço teórico capaz de sustentar o transporte como um direito fundamental do indivíduo e garantir o financiamento do transporte por toda a sociedade através, por exemplo, da criação de fundos específicos para tal.

\section{DISCUSSÃO E CONCLUSÃO}

Clayton e Williams (1999) colocam que existem dois tipos de princípios de justiça distributiva: os princípios estritamente igualitários, que afirmam que não é justo que alguns estejam em pior situação que outros, e os prioritários, que favorecem os piores posicionados. Os autores afirmam que filósofos estritamente igualitários estão preocupados com a desigualdade e os prioritários, com as necessidades mais urgentes. A igualdade de recursos, proposta por Dworkin, é uma das teorias preocupadas com a desigualdade.

Martens (2016) propõe outra forma de enxergar essa divisão, classificando as teorias de justiça como comparativas ou analíticas. Para o autor, o objetivo de expandir uma teoria de justiça ao domínio dos transportes só pode ser alcançado através de uma teoria de justiça analítica robusta, capaz de expandir a apreciação à esfera da acessibilidade. Deste modo, as teorias voltadas a necessidades específicas do indivíduo (comparativas ou prioritárias) como a Abordagem das Capabilities, de Amartya Sen e Martha Nussbaum não atendem ao pré-requisito e dependem fortemente dos exemplos dados. Outro problema é que teorias comparativas raramente podem ser comparadas em apenas uma dimensão, o que, no geral, leva a pessoas diferentes terão conclusões diferentes para o que constitui uma situação de justiça. 
As teorias utilitaristas, são igualitárias e analíticas, entretanto, possuem uma tendência classista ao considerar, por exemplo, que se um indivíduo gera mais renda, os seus desejos (podendo ser o desejo de se movimentar) devem ser priorizados, mesmo que isso leve pessoas com menos capacidade de geração de renda a ficarem desalojadas. Ou seja, na vida real em uma sociedade com discrepâncias de condição socioeconômica e de infraestrutura espacial e de transportes o uso de teorias utilitaristas tende a reforçar o ciclo vicioso das desigualdades, inclusive as de transporte.

A Teoria de Justiça de Rawls, por sua vez, também é igualitária e analítica. Entretanto, não é possível estender essa teoria a uma área específica sem cair na armadilha de realizar julgamentos de valor. Para Martens (2016) incorporar acessibilidade à teoria de Rawls enfraqueceria a sua robusta Teoria de Justiça. Seria necessário considerar a acessibilidade como um bem primário adicional, o que criaria um problema de comparação interpessoal, algo considerado absurdo pelo próprio Rawls (Rawls, 2003, pg. 72).

A teoria da Igualdade de Recursos de Dworkin, também igualitária e analítica, permite a expansão da teoria para diferentes bens, ou áreas específicas, sem precisar construir uma nova teoria mais abrangente. Além disso, Dworkin liga a equidade de distribuição diretamente ao custo de prover a distribuição desejada. A equidade não é idealizada em uma sociedade onde não existe escassez de recursos, considerando os sacrifícios necessários para uma distribuição justa o que é feito através do esquema de seguros. Por estas características, e pela situação de desigualdade socioeconômica encontrada nos países de desenvolvimento, considera-se que esta é a abordagem mais adequada para referir-se a questões de equidade e justiça em transportes no Brasil.

\section{REFERÊNCIAS}

Beyazit, E. (2011) Evaluating social justice in transport: lessons to be learned from the capability approach. Transport reviews, v. 31, n. 1, p. 117-134. DOI: 10.1080/01441647.2010.504900

Clayton, M. (2002) Liberal equality and ethics. Ethics, v. 113, n. 1, p. 8-22. DOI: 10.1086/341324

Clayton, M. e A. Williams (1999) Egalitarian justice and interpersonal comparison. European Journal of Political Research, v. 35, n. 4, p. 445-464. DOI: 10.1111/1475-6765.00455

Dias, M.C. (2018) A perspectiva dos funcionamentos: um olhar ecofeminista decolonial. Revista Direito e Práxis, v. 9, n. 4, p. 2503-2521. DOI: 10.1590/2179-8966/2018/37972

Dworkin, R. (1981) Is There a Right to Pornography? Oxford Journal of Legal Studies, vol. 1, no. 2, pp. 177-212.

Dworkin, R. (2001) Do Values Conflict? A Hedgehog's Approach. Arizona Law Review, vol. 43:2.

Dworkin, R. (2002) Sovereign Virtue Revisited. Ethics, vol. 113, outubro, pp. 106-143. D0I: 10.1086/341579

Dworkin, R. (2005) Uma Questão de Princípio. Editora Martins Fontes.

Dworkin, R. (2011) Justice for hedgehogs. Harvard University Press.

Dworkin, R. (2012) Ronald Dworkin on the Unity of Value. Philosophy bites, podcast. 09 mar 2012. Disponível em: $<$ https://open.spotify.com/episode/2NhkZac4wPWXImwIY3yub3?si=tgXIXUwvRgCOu9U2z79ZAw>. Acesso em: 20/10/2021

Farrington, J e C. Farrington (2015) Rural accessibility, social inclusion and social justice: towards conceptualization. Journal of Transport geography, v. 13, n. 1, p. 1-12. DOI: 10.1016/j.jtrangeo.2004.10.002

Furquim, L. (2010) O liberalismo abrangente de Ronald Dworkin. 2010. Tese (Doutorado). Ciência Política. Universidade de São Paulo, São Paulo. Disponível em: < https://www.teses.usp.br/teses/disponiveis/8/8131/tde-02122010-111403/publico/2010_LiliandeToniFurquim.pdf > Acesso em: 21/10/2021.

Guest, S. (2009) How to criticize Ronald Dworkin's theory of law. Analysis, v. 69, n. 2, p. 352-364. DOI: 10.1093/analys/anp050

Hananel, R. e J. Berechman (2016) Justice and transportation decision-making: The capabilities approach. Transport Policy, v. 49, p. 78-85, 2016. DOI: 10.1016/j.tranpol.2016.04.005

Harvey, D. (1990) The Condition of Postmodernity: an enquiry into the origins of cultural change. Malden, MA/Oxford, Blackwell.

Hausman, D.; M. Mcpherson e D. Satz (2016) Economic analysis, moral philosophy, and public policy. Cambridge University Press.

Khisty, C. (1996) Operationalizing concepts of equity for public project investments. Transportation Research Record, v. 1559, n. 1, p. 94-99. DOI: 10.1177/0361198196155900112 
Kymlicka, W. et al. (2002) Contemporary political philosophy: An introduction. Oxford University Press. Oxford.

Langmyhr, T. (1997) Managing equity: the case of road pricing. Transport Policy, v. 4, n. 1, p. 25-39. D0I: 10.1016/S0967070X(96)00031-5

Lima, J. (2020) Mobilidade e equidade: um olhar da justiça distributiva sobre o uso da motocicleta em Alagoas. Tese (Doutorado). Engenharia Civil. Universidade Federal de Pernabuco. Recife. Disponível em: < https://repositorio.ufpe.br/bitstream/123456789/37729/1/TESE\%20Jessica\%20Helena\%20de\%20Lima.pdf > Acesso em: 21/10/2021.

Nussbaum, M. (2007) Frontiers of justice: Disability, nationality, species membership. Harvard University Press.

Nussbaum, M. (2011) Creating capabilities. Harvard University Press.

Martens, K. (2011) Substance precedes methodology: on cost-benefit analysis and equity. Transportation, v. 38, n. 6, p. 959. DOI: $10.1007 / \mathrm{s} 11116-011-9372-7$

Martens, K. (2016) Transport justice: Designing fair transportation systems. Routledge.

Pereira, R.; T. Schwanen, T e D. Banister (2017) Distributive justice and equity in transportation. Transport reviews, v. 37, n. 2, p. 170-191. DOI: $10.1080 / 01441647.2016 .1257660$

Pirie, G. H. (1983) On spatial justice. Environment and Planning A, v. 15, n. 4, p. 465-473. DOI: 10.1068/a150465

Rawls, J. (1971) A theory of justice. Cambridge, MA: p, University.

Rawls, J. (1982) The basic liberties and their priority. The Tanner lectures on human values, v. 3, p. 3-87.

Rawls, J. (2003) Justiça como equidade: uma reformulação. Martins Fontes.

Ribeiro, C. (2015) Justiça social e equidade em saúde: uma abordagem centrada nos funcionamentos. Saúde e Sociedade, v. 24, p. 1109-1118. DOI: $10.1590 /$ S0104-12902015137819

Roemer, J. (1998) Theories of distributive justice. Harvard University Press.

Sen, A. (1979) Equality of what? The Tanner lecture on human values, v. 1.

Sen, A. (2017) What do we want from a theory of justice? In Theories of Justice (pp. 27-50). Routledge.

Sen, A. (2009) The idea of justice. Harvard University Press.

Van Wee, B. (2012) How suitable is CBA for the ex-ante evaluation of transport projects and policies? A discussion from the perspective of ethics. Transport Policy, v. 19, n. 1, p. 1-7. DOI: 10.1016/j.tranpol.2011.07.001 
